\title{
Materiais da/de Arte para as crianças
}

\section{Materiales de arte para niños}

\section{Art materials for children}

Susana Rangel Vieira da Cunha'

https://orcid.org/0000-0002-5246-0469

\begin{abstract}
Resumo: Este artigo enfoca os materiais que constituem as produções da Arte e os materiais ofertados às crianças nos contextos escolares. Entende-se que, atualmente, no campo da Arte, qualquer material é considerado como veículos para configurar ideias e, nas escolas, perduram os materiais tradicionais. $O$ que são materiais da Arte de hoje? Como a Escola entende os materiais da Arte? São as questões que guiaram as reflexões sobre a presença/ausência dos materiais da Arte, bem como seus usos nos contextos educativos. Para tanto, foram utilizados dados de pesquisas desenvolvidas no nível de graduação e pós-graduação de uma Faculdade de Educação e pesquisas em redes sociais. Compreende-se que as transformações operadas no campo da Arte desde metade do séc. XIX chegam vagarosamente nos contextos educativos infantis, havendo incompreensão da necessidade de trazer outros materiais para as crianças ampliarem seus processos de investigação e criação.
\end{abstract}

Palavras-chave: Materiais. Educação Infantil. Arte Contemporânea.

Abstract: This article focuses on the materials that make up the productions of Art and the materials offered to children in school contexts. It is understood that currently in the field of Art any material is considered as a vehicle for configuring ideas and in schools the traditional materials endure. What are today's Art materials? How does the School understand the materials of Art? These are the questions that guided reflections on the presence I absence of Art materials, as well as their uses in educational contexts. For this purpose, data from research developed at the undergraduate and graduate level of a Faculty of Education and research on social networks were used. It is understood that the transformations carried out in the field of Art since the middle of the century. $\mathrm{XIX}$ arrived slowly in children's educational contexts, with a lack of understanding of the need to bring other materials for children to expand their research and creation processes.

Keywords: Materials. Kindegarden. Contemporary Art.

Resumen: Este artículo se centra en los materiales que componen las producciones de Arte y los materiales que se ofrecen a los niños en los contextos escolares. Se entiende que actualmente en el campo del Arte cualquier material es considerado como un vehículo para configurar ideas y en las escuelas perduran los materiales tradicionales. ¿Qué son los materiales de arte de hoy? ¿Cómo entiende la Escuela los materiales de Arte? Estas son las preguntas que guiaron las reflexiones sobre la presencia / ausencia de materiales artísticos, así como sus usos en contextos educativos. Se utilizaron datos de investigaciones desarrolladas a nivel de grado y posgrado

'Pós-Doutora em Arte e Educação, Universitat de Barcelona. Doutora e Mestra em Educação, Licenciada em Artes Plásticas, UFRGS. Pesquisadora e Professora Associada aposentada Faculdade de Educação, UFRGS. Proprietária do Amarelo Van Gogh: Consultoria em Arte \& Educação. E-mail: trabalhosusana@gmail.com

Olhar de professor, Ponta Grossa, v. 24, p. I-25, e-17695.037, 202 I.

Disponível em <https://revistas2.uepg.br/index.php/olhardeprofessor> 
de una Facultad de Educación e investigaciones en redes sociales. Se entiende que las transformaciones llevadas a cabo en el campo del Arte desde mediados de siglo XIX llegó lentamente a los contextos educativos de los niños, con una falta de comprensión de la necesidad de traer otros materiales para que los niños amplíen sus procesos de investigación y creación.

Palabras-clave: Materiales. Escuela Infantil. Arte Contemporáneo.

\section{Quais teus materiais?}

Prendedores de roupas, engradado, meia, sapato, rosário, brinquedo, talheres, guardanapo de crochê e de papel, pelotine, conduíte, trincha, aplainador, soquete, formas de empada e de bolo, bacia, tacos de parquê, sacola de compras, guarda-chuva, parafuso, desentupidor de pia, escorredor de massa, livros, sal, areia, troncos de árvores, carvão, tijolo, assento de cadeira, chocolate, gelo, barbante, fitas adesivas, cera depilatória, ralador, mangueira. Seria uma lista de materiais que estão faltando na minha casa? NÃO!!!! É uma lista de materiais que vi em produções contemporâneas da Arte.

Folhas brancas, cola líquida e em bastão, pincéis, tinta guache ou têmpera, giz pastel, giz de cera, lápis de cor, conjunto canetas hidrocor, aquarela, argila, massa de modelar. E esta lista, o que é? Certamente, todxs reconhecem como uma lista escolar de materiais de Arte. Como é perceptível, na primeira lista, há materiais ou objetos de procedências diversas, já na segunda, é uma lista reduzida e semelhante ao resultado da pesquisa do Google quando buscamos: "materiais de arte na educação infantil". Evidentemente, assim como existem infinitos materiais que constituem as obras da Arte de hoje, também encontramos em nossa busca algumas listas de materiais escolares mais amplas. No entanto, o que se evidencia nas listas é uma constância e redução nos materiais de Arte nas escolas e a versatilidade e abundância nos materiais da Arte.

O título do artigo "Materiais da/de Arte para as crianças" é uma provocação e um convite que faço para refletirmos e dialogarmos sobre o que a Arte considera como materiais e o que a Escola utiliza como materiais para as propostas em Arte. Para demarcar essa diferença, brinco com a sutil diferença da preposição de e da quando ela é utilizada na forma de contração com o artigo a, para anunciar a distância entre a Arte que circula há mais de 100 anos e a arte escolar. E é esse o enfoque deste artigo: produzir reflexões sobre os materiais da Arte, tradicionais ou qualquer outro, e os materiais que comumente as escolas disponibilizam às crianças.

Entre tantas temáticas urgentes da Arte na Educação, o primeiro motivo da escolha é porque, como professora de Arte, tenho fascínio sobre a alquimia dos materiais e as possibilidades que eles ofertam para configurar nossos modos de ver o mundo. Em toda a minha docência em arte com crianças, jovens e adultos, trabalhei na forma de atelier, pois creio que experienciar os materiais expande a nossa compreensão histórica, social, cultural, pedagógica, cognitiva, sensorial e sensível. 
Entendo que eles sendo veículos, meios, para dar formas aos nossos pensamentos e expressão, deveriam ser protagonistas e não pensados e utilizados como consequência das proposições em Arte.

A cena pedagógica em Arte poderia, muitas vezes, partir da investigação, exploração e descobertas dos materiais. Os materiais convidariam/provocariam as crianças às descobertas e ao surgimento de outras configurações. O modo como a artista Lia Menna Barreto transforma brinquedos e outros objetos em seus trabalhos poderia ser referência, no contexto educacional, para repensar no quanto os materiais são centrais nos processos de criação. Sobre como a artista utiliza os materiais: "É a materialidade das coisas, e sua potencialidade expressiva, que lhe interessa” (BOHNS, 2003), “(...) em nenhum momento parece estar interessada em que brinquedos se reduzam a metáforas antropomórficas. O que the interessa, de fato, são as possibilidades de, em trabalhando com brinquedos, intervir numa ordem dos objetos" (HERKENHOFF, 1995). Assim como Lia mergulha a fundo na potencialidade dos materiais, sugiro que os materiais possam ser mais explorados nos contextos escolares como veículos e, principalmente, como um dos propulsores do pensamento pedagógico em Arte.

O segundo motivo que me fez abordar os materiais decorre da escassez de pesquisas, artigos, reflexões acadêmicas no contexto brasileiro, e também internacional, sobre a importância do conhecimento e da exploração dos materiais, sejam eles os tradicionais, sejam os atuais. Entendo que a escola enfatiza o desenvolvimento de projetos, proposições, como, por exemplo: autorretrato seria a proposição, riscantes, marcadores de suportes, fotografias, espelhos seriam os materiais escolhidos para dar corpo à proposição do autorretrato. Dificilmente uma professora pensa/começa o trabalho pedagógico em Arte pelos materiais, oferecendo espelhos, riscantes, fotografias para ver como o conhecimento e experimentações das crianças com os materiais poderiam desencadear proposições. De maneira semelhante, as discussões e reflexões acadêmicas centram-se também nos aspectos pedagógicos da Arte na Escola ou em como as crianças pensam, produzem nas diferentes linguagens da Arte e, assim, há poucas discussões e reflexões sobre os materiais. Desse modo, é importante debruçarmo-nos sobre a importância deles nos espaços escolares e acadêmicos, contribuindo para que eles passem a ter destaque nas cenas pedagógicas.

O artigo estabelece diálogos com a Arte e a Educação, trazendo artista e obras, experiências pedagógicas com materiais em contextos escolares de docência e pesquisa, bem como materiais recolhidos em grupos virtuais de Educação Infantil. Essas referências serviram para as reflexões aqui desenvolvidas.

Parto de um breve panorama histórico sobre as transformações dos materiais e seus usos na Arte, porque acredito que este campo de conhecimento possibilitará pensá-la nos contextos educativos em qualquer nível de educação. Outros campos do conhecimento são fundamentais para 
pensar o trabalho pedagógico em Arte, mas se ele não estiver alicerçado na Arte, estaremos fazendo outro tipo de trabalho e impedindo que as crianças usufruam de processos singulares de transformações matéricas, estéticas e sensíveis.

Posteriormente, são apresentadas algumas denominações utilizadas hoje aos materiais, a concepção de desenho expandido que muitos artistas valem-se e como eles inspiram-nos em trabalhos pedagógicos, bem como as modificações na pintura e os modos de pintar. Ao final, discuto o quanto as pedagogias culturais generificam o uso dos materiais. Ao longo do artigo, há diálogos constantes com artistas e obras que transformaram a Arte e possibilitam-nos pensar a Arte nos contextos escolares.

\section{O que são os materiais da Arte?}

Os materiais na Arte são "veículos" para formulação de ideias. Até a metade do século XIX, serviam para a representação ou criação de realidades e, após, quando a Arte rompeu a representação análoga ao real observável, os artistas, com suas experimentações, com linguagens e materiais, possibilitaram outros olhares para a produção artística, modos de fazer Arte e relacionarmo-nos com ela. Vale lembrar que as temáticas da Arte, até meados do séc. XIX, construíram, repetidamente, com algumas variações, concepções de mundos, homens (muitos), mulheres (algumas), crianças (poucas), naturezas idílicas, crenças, bravura, beleza, feiura, exotismos e também mostraram formas de poder e submissão, privilégios, invisibilizando grupos socioculturais e enaltecendo outros. Já no séc. $X X$, as temáticas passaram a ser problematizações locais ou transnacionais de acontecimentos que perpassam a vida coletiva.

As mudanças operadas pelas Vanguardas Artísticas, no final séc. XIX, transformaram as concepções de Arte, habilidade, beleza, criatividade, materiais, suportes, instrumentos e, assim também, problematizaram o conhecimento acumulado nesse campo. Artistas Impressionistas, Expressionistas, Fauvistas, Cubistas, Futuristas, Surrealistas, Dadaístas e filiados em outras tantas correntes artísticas iniciaram experiências até então nunca imaginadas com materiais e técnicas, miscigenaram linguagens tradicionais como a pintura e o desenho sem se preocuparem em enquadrálas nas definições existentes.

$\mathrm{Na}$ esteira das mudanças no início do séc. $\mathrm{XX}$, artistas, como Picasso e Braque, inseriram materiais banais, como jornais, capas de revistas, assentos de cadeiras para compor suas produções gráfico-plásticas. No mesmo período, Duchamp enviou, para Salões de Arte e exposições, objetos industrializados, denominados de ready made, como obras de arte e também para contestar a ideia vigente de Arte. Assim, ao introduzirem materiais comuns na constituição das obras, os artistas adulteraram conceitos seculares da própria Arte. 
Apesar das mudanças, muitas vezes quando pensamos em materiais de Arte, relacionamo-los com os meios de configurar as linguagens tradicionais como a pintura, desenho, escultura e gravura, entre eles: tinta, grafite, carvão, mármore, argila. No entanto, a partir do final do século XIX, os modos de produzir Arte foram radicalmente modificados, outras linguagens como a colagem e bricolagem passaram a ser consideradas como Arte, também começaram as hibridizações entre as linguagens, possibilitando, assim, o alargamento e a experimentação de qualquer material no campo da Arte ocidental.

O pintor Jackson Pollock (1912-1956), em meados do século XX, apontava para a ruptura dos materiais tradicionais da Arte, segundo ele: "Objetos de todos os tipos são materiais para nova arte: tinta, cadeira, luzes elétricas e néon, fumaça, água, meias velhas, um cachorro, filmes, mil outras coisas que serão descobertas pela geração atual de artistas. (KAPROW apud FERREIRA; COTRIN, 2006, p. 44).

Atualmente, nas exposições de Arte Contemporânea, há uma infinidade de materiais de uso cotidiano compondo as obras: prendedores de roupas, lupas, brinquedos infantis, objetos decorativos e utilitários, absorventes íntimos, panelas, guardanapos, fumaça, gelo, nuvens, fuligem, cera depilatória, roupas, cabelos, sapatos, sal, água, revistas, jornais, livros, TVs, rádios, projetores, motores, etiquetas, sacolas, malas, pentes, escovas de cabelo, armários, talheres, pratos, troncos, árvores, grãos, folhas, pedras, tijolos, entre tantos outros objetos e materiais passam a ser a "matéria prima" da Arte.

\section{Mudança nos significados dos objetos e materiais}

Artistas como Elida Tessler, Ai Wei Wei, Marepe, Erwin Wurm, Joana Vasconcelos, Cildo Meirelles, Marcia X, entre tantos outros, apropriam-se de materiais banais e desconstroem com suas montagens a relação unívoca significante-significados, de modo que passamos a ver/entender aqueles objetos de outras formas, atribuindo outros significados a um mesmo significante. Ou seja, os objetos corriqueiros são os materiais da Arte, ao serem colocados em outros contextos e composições, eles ganham outro sentido devido aos arranjos realizados pelos artistas. Objetos em uma prateleira de um bazar são apenas objetos de uso, no entanto, se agrupados de outras maneiras, passam a ter outra ressonância.

Sobre a vertente da Apropriação, Chiarelli (2002, p.21) explica como simples objetos transformam-se: “Apropriar-se é matar simbolicamente o objeto ou a imagem, é retirá-la do fluxo da vida - aquele contínuo devir, que vai da concepção/produção até a destruição/morte, colocando-os lado a lado a outros objetos, com intuitos mais diversos." As obras de Nelson Leirner, Lia Menna Barreto, Sandro Ka, Banksy, Léon Ferrari, Marina Camargo, Tunga, compostas com simples objetos 
mostram-nos como os artistas, ao se apropriarem dos objetos, adulteram os significados e abrem nossos olhos para vê-los de outro modo.

Ressalto que as crianças também se apropriam dos objetos, materiais e atribuem outros significados a eles, criando narrativas inusitadas. Entretanto, raramente a Escola percebe a proximidade entre o pensamento poético das crianças com o dos artistas de hoje. Se não há conexões entre Arte Contemporânea e modos de ensinar Arte, passam despercebidas as combinações frequentes que as crianças realizam com os objetos e materiais. Sendo assim, essas produções das crianças não são vistas como possíveis disparadores para criação de cenas pedagógicas em Arte.

Figura I: Apropriação de objetos e materiais pelas crianças
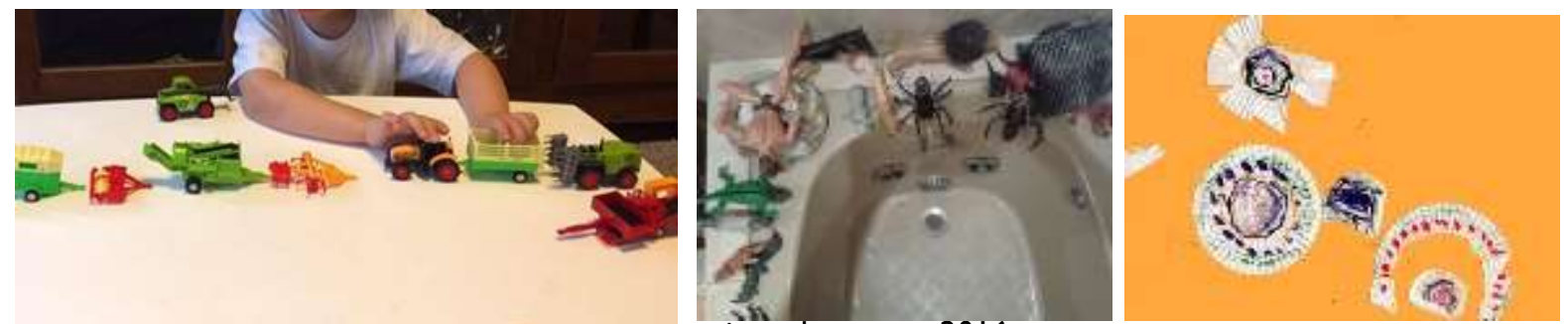

ronte: arquivos da autora, 2016.

De certo modo, as concepções de Arte, na maioria das escolas, ainda fundam-se na Arte de outro tempo, em que a habilidade, a verossimilhança, as temáticas, as linguagens "puras", os materiais específicos formulam ideias sobre como a Arte deve ser trabalhada com as crianças. Concordo com Ostetto, quando ela explicita o distanciamento entre os modos das crianças expressarem-se e os modos da escola desenvolver o trabalho pedagógico em Arte com as crianças:

Crianças fazem poesia com a palavra, com os objetos, com o corpo inteiro. Elas pensam metaforicamente e expressam seu conhecimento do mundo valendo-se das muitas linguagens criadas e recriadas na cultura em que estão inseridas. Apresentar desafios para os quais não se espera uma única resposta é algo distinto de oferecer uma atividade "para fazer assim", para chegar naquilo que o professor determinou que seria o produto final. Implica em considerar especificidades de um campo de conhecimento que não se define pela norma, pois não há regras fixas no modo de produção da arte, suas linguagens são territórios sem fronteiras. Pesquisar, mergulhar no desconhecido para testar novos materiais e formas, experimentar diferentes elementos ainda não apropriados, integram o fazer artístico (OSTETTO, 2010, p. 280).

Os modos diferenciados de usar os materiais tradicionais pictóricos e gráficos foram modificados a partir das Vanguardas Artísticas e acentuaram-se radicalmente no século $X X$ e $X X I$. Entretanto, o deslocamento de objetos de seu contexto, assim como a utilização de materiais do cotidiano, presentes nas produções contemporâneas, não costuma estar presente nas escolas. 
Os materiais-veículos tradicionais que sustentaram a produção da arte secular como carvão, pastel seco, sanguínea (uma espécie de giz vermelho), papéis, tintas, telas, madeiras, mármores, argilas, pedras, metais, gesso, entre outros, convivem e dialogam com os diferentes materiais-veículo vindos de bazares, ferragens, supermercados, lojas de roupas, calçados, móveis, construção civil, etc. Podemos dizer que eles perderam o protagonismo na produção contemporânea da Arte e o título soberano de "materiais da Arte", tendo em vista que hoje qualquer material, dos perenes aos efêmeros, como fumaça, gelo, alimentos, vento, são considerados como materiais-veículo da Arte.

\section{Em busca de denominações para os materiais de Arte na Escola}

Por muito tempo, denominamos os materiais tradicionais do campo das Artes como "materiais expressivos" por entendermos que eles possibilitavam configurar um dos principais atributos da produção em Arte: expressar algo para alguém e, por isso, frequentemente, ouvimos a pergunta: o que o artista quis transmitir/dizer? Os materiais seriam os meios pelos quais seriam "comunicados" os sentimentos dos artistas, por isso, a denominação: materiais expressivos.

Contudo, com as mudanças operadas no campo da Arte no século $X X$, a expressão, entendida como transmissão de sentimentos do artista ao público, deixou de ser uma das principais características e outras passaram a serem atribuídas às obras de Arte, entre elas: deslocar pensamentos, provocar questionamentos, produzir diferentes interpretações possibilitando ao público a coautoria, uma vez que as obras não têm mais a intenção de enviar mensagem "única" dos sentimentos do artista ao público, mas proporcionar múltiplas leituras.

Concordo com Tiburi (2012, p. 20), quando ela expressa a "desacomodação" como um dos principais atributos da Arte do nosso tempo: "A obra contemporânea quebra com nossa ideia habitual de arte e é por isso que tantos se sentem incomodados ou, pelo menos, desacomodados, diante de suas obras. A desacomodação é o que de melhor uma obra pode nos dar".

Se as concepções de Arte, materiais, relações público-obra, intencionalidade dos artistas, foram modificadas, é necessária uma revisão na expressão "materiais expressivos" nos contextos escolares. Seguindo a ideia que Arte deve desacomodar-nos conforme Tiburi, seria mais adequado denominá-los de "materiais desacomodadores", ou "perturbadores", pois, assim, estariam em consonância com as proposições da Arte Contemporânea.

Circulam, nos contextos escolares, algumas denominações para os materiais de Arte, uma delas vem do campo dos Estudos Lúdicos: "brinquedos de longo alcance” (Leontiev, 1994), que é transposta para o trabalho pedagógico em Arte, seriam "materiais de longo alcance" aqueles que possibilitam atribuir vários significados, usos e oportunizariam acionar os processos inventivos das crianças. São materiais comuns, sucatas e da natureza, como colheres de pau, copos, embalagens, 
guardanapos, roupas, caixas, prendedores, bacias, retalhos de madeira e tecidos, panelas, pedras, cacos de tijolos, galhos, troncos, cestos, penas, entre tantos outros materiais banais que as crianças passam a atribuir significados em torno deles. Nesse processo de transformar materiais em algo, as crianças fingem que um retalho de madeira é um tubarão feroz e transformam um fragmento de vidro em uma joia rara (CUNHA, 2019, p. II).

Dentro dessa mesma ideia de aproveitar objetos/materiais comuns como geradores de significados múltiplos, há a expressão "materiais não estruturados", vinda das experiências de Reggio Emilia. Segundo Gandini (2012, p. 192), uma das pesquisadoras de Reggio, materiais comuns possibilitam a "capacidade de construir novas conexões entre pensamentos e objetos, promovendo inovações e mudanças, pegando objetos conhecidos e criando novas conexões".

Ambas as expressões alinham-se com o que a Arte Contemporânea vem realizando com os objetos comuns: produzir outros significados e relações. Desde Duchamp e, posteriormente, o movimento da Pop Art iniciado na metade dos anos 50, na Inglaterra, com o grupo do artista David Hamilton, depois, absorvida nos anos 60 pelo artista norte-americano Andy Warhol, os objetos industrializados descartados ou em uso passaram a ser os materiais da Arte.

Outra denominação, que também está próxima do que entendemos por Arte Contemporânea, é a expressão 'materiais provocadores”, cunhada por Diefenthäler (2009) em sua dissertação: “A gente pode fazer casa do jeito que a gente quiser?": ações propositoras e materiais provocadores ampliando o imaginário infantil. Para a autora, há dois tipos de Materiais Provocadores, o primeiro seria artefatos produzidos a fim de incentivar diferentes experimentações, interações, explorações. $O$ segundo seria todos aqueles materiais, de largo alcance e tradicionais, que buscam problematizar conceitos, experimentações, comportamentos engessados que fazem parte dos cotidianos escolares. Lembro que a ideia de utilizar artefatos e materiais não convencionais no trabalho pedagógico com crianças inicia com Fröebel (1782 - 1852), porém, hoje, os Materiais Propositores adquirem outras funções no trabalho pedagógico em Arte. Os "dons", objetos criados por Fröebel, tinham algumas regras que as crianças deveriam seguir e dominar para melhor aproveitamento, enquanto os Materiais Propositores são de manipulação exploratória e visam a diferentes usos e processos de criação pelas crianças.

Entendo que a ideia de os materiais serem percebidos como provocadores também se aproxima de uma das características da Arte na contemporaneidade, tendo em vista que muitas obras têm o intuito de nos provocar a pensar/criar/relacionar. Concordo com Canton (2013, p. 139), quando ela aponta uma das principais mudanças efetuadas pela Arte Contemporânea, segundo a autora: “(...) a ação artística contemporânea se engaja em tentativas de restabelecer na arte uma conexão com o observador de forma a incitar nele algum tipo de postura diante do mundo e da vida". 
Outra proposta diferenciada em relação aos materiais e suas utilizações é o Projeto Createctura, que é a interseção das áreas do design, arte e pedagogia, desenvolvido pela espanhola Irene Fernández Álvarez. A mentora do projeto denomina a composição dos materiais de 'binômios fantásticos', segundo ela:

Propomos em nossa prática todos os tipos de binômios fantásticos de objetos, materiais, espaços, escalas, tempos, assuntos, disciplinas e pessoas. Objetos e materiais sem vinculação prévia como limpadores de copos e sal, quando combinados, tornam-se complementares e oferecem novas possibilidades de exploração e de expressão gráfica e de movimento. (...) Assim, com os materiais mais banais podemos criar espaços de espanto. Com objetos recuperados, anônimos, desconectados de sua função original, podemos criar lugares que despertam nossa curiosidade. (...) Ao combinar objetos onipresentes no mundo infantil com outros distantes do campo educacional, podemos criar binômios fantásticos que geram novas relações, ações e possibilidades de experimentação. Se os multiplicarmos no espaço, podemos inventar composições efêmeras e paisagens envolventes que nos ajudam a nos reconectar com nosso lado mais sensível (Material disponibilizado para alunxs do curso on line Introducción Bases Creactectura, outubro 2020).

Ressalto que ao oferecer os materiais às crianças, sejam simples lápis, sejam metros de conduíte, é necessário armar uma cena pedagógica com o intuito das crianças conhecerem, explorarem, experimentarem e criarem com os materiais.

A professora de crianças e pesquisadora (Borges, 2017, p. 53) sugere como podem ser escolhidos e utilizados os materiais:

e) é desejavelmente que apresente às crianças os materiais disponíveis sem que haja um direcionamento prévio ao uso, por exemplo: um guarda-chuva para além de nos proteger da chuva pode ser um excelente suporte de pintura ou um ventilador de gigantes... deixe e possibilite que as crianças manipulem e façam usos próprios dos materiais;

f) procure evitar os materiais convencionais disponíveis nas escolas e destinados para as aulas de arte, como: caneta hidrocor, tinta guache e folha A3 branca...em tempos de sustentabilidade e de uma consciência ambiental global opte pelo que há de descartável: bonecas velhas que ninguém brinca e que iriam para o descarte, caixas de papelão dos mais diferentes tamanhos, retalhos de roupas, tinta feita de beterraba, a argila que endureceu ou a terra que tem no pátio...

A respeito dos materiais não convencionais, ou inusitados, conforme Holm (2007, p. II), denominações utilizadas pela autora, ela interroga-nos sobre seus usos: "Quando se oferecem diferentes possibilidades às crianças pequenas, usando materiais próprios para que elas criem imagens, que experiências poderíamos vivenciar junto com elas? Onde teria lugar esta experiência? Que materiais seriam mais adequados ao uso? O que fazer?" Entendo que não basta simplesmente oferecer materiais convencionais e não convencionais às crianças, é necessário criar uma cena pedagógica ao oferecê-los, explorando as possibilidades e potencialidades deles, usá-los de outras formas e não os pensar apenas como uma finalidade pré-estabelecida para servir uma "temática" do planejamento. 
Concordo com a sugestão de Holm (op. cit., p. II) sobre como as professoras deveriam pensar e agir frente aos materiais: "Abra a mente para o uso dos materiais inusitados. São inúmeros os materiais disponíveis num mundo aberto a várias interpretações".

Adotar uma denominação contemporânea aos materiais-veículo não garante às crianças formas inventivas de trabalhar com eles. Assim como a Arte de hoje desafia-nos, desacomoda, atiça, provoca, os materiais quando ofertados às crianças também deveriam estar dentro dessa perspectiva, caso contrário a forma estereotipada da flor, sol, nuvem, árvore, grama, passarinho será replicada com qualquer material.

\section{Desenho expandido}

No campo do desenho, os materiais riscantes tradicionais passaram a ser explorados de outros modos e o papel passa a ser apenas mais um suporte entre tantos outros. William Kentridge "desenha com carvão sobre uma tela, apaga e desenha novamente sobre essa mesma tela, criando uma forma de palimpsesto que evidencia os rastros visíveis" (MARCOLINO E SILVA, 2006, p. 279), seus desenhos rasgados, recompostos são animados com stop motion e compõem instalações, performances, segundo depoimento do artista sobre o que é o desenho:

(...) as vezes $\circ$ trabalho permanece um desenho. Algumas vezes o desenho torna-se parte de um livro, ou um flipbook, ou é filmado e alterado tornando-se uma animação, ou torna-se parte de uma montagem teatral, seja como cenário ou parte substancial da narrativa, ou pode ser passado para o papelão e tornar-se uma escultura, ou o papelão pode ser empilhado e esculpido. Cada uma dessas transformações está testando qual seriam os possíveis significados da imagem (KENTRIDGE, 2012, apud MARCOLINO E SILVA, p. 280).

Outros artistas, como Tomas Barth e Teresa Poester, utilizam canetas esferográficas, como riscantes, um material desconsiderado até recentemente no campo das poéticas da Arte. $\mathrm{Na}$ exposição de Poester: "Até que meus dedos sangrem", 2019-2020, foram utilizadas 600 canetas BIC vermelhas para a obra-título da mostra, sobre um linóleo branco fosco com dimensão de aproximadamente 20 metros quadrados. Junto ao desenho, a artista mistura outras linguagens como a gravura, fotografia e vídeo. Conforme o curador da exposição, Eduardo Veras (2019): “Teresa Poester vem se dedicando nos últimos anos a investigações de caráter experimental sobre possíveis fusões do desenho - ou do gesto de desenhar - com outras linguagens expressivas, sejam a fotografia, o livro de artista, a gravura a performance, o videoperformance e, mais recentemente, a animação".

Assim como Kentridge, Poester expande a linguagem do desenho e os materiais-veículo que o constituem. Ambos os artistas, assim como tantos outros, fazem uma renovação inusitada daquilo que comumente conhecíamos e designávamos como desenho. 
No campo da Educação, a ideia de desenho expandido tem sido desenvolvida pelo Segni Mossi, formado pela dupla de artistas, formadores e atelieristas italianos Alessandro Lumare, artista plástico, ilustrador, e Simone Lobefaro, coreógrafa, em propostas que misturam desenho e movimento. No site SEGNI MOSSI, o trabalho é definido como:

(...) um projeto de movimento e sinalização gráfica para crianças e adultos. Partindo do princípio de que a dança e o desenho são duas formas de deixar uma marca, pensamos em um trabalho onde fosse possível vivenciar as consequências desse insight. Não é uma atividade multidisciplinar, mas sim uma oportunidade de redescobrir juntos uma unidade entre duas línguas que normalmente são consideradas separadas. Em Segni Mossi tanto as produções gráficas como as produções de dança são vestígios de processos: interessa-nos viver essas experiências.

Os objetivos do trabalho do Segni Mossi estão longe da ideia do desenho como representação e de ter, como finalidade, um produto concreto e "acabado", tão comum em nossas escolas. Segundo os autores:

(...) valorizar o traço libertando-o de qualquer subordinação representativa; ter mais confiança em usar nossos corpos como ferramentas de comunicação; explorar a conexão entre as qualidades expressivas dos movimentos corporais e as qualidades expressivas do traço; considerar a experimentação como método de trabalho; prolongar o processo criativo e não o resultado; estimular o pensamento crítico e o sentimento estético, lúdico e criativo.

Para que o desenho, assim como as outras linguagens, modifique-se na Escola é necessária uma atualização do que são os materiais e o desenho hoje, para tanto, a ampliação de repertórios é imprescindível.

\section{Desenho com fitas adesivas sobre paredes, portas, mesas e espelhos}

Em várias situações de supervisão de estágio curricular, pesquisa em escolas infantis, cursos de formação de professoras e agora nos grupos de professoras de Educação Infantil nas redes sociais, noto que as concepções e ações pedagógicas em Arte estão longe do contexto da produção artística atual. Meu questionamento ao longo de anos e, atualmente, é: Há mais de um século a Arte transformou-se e qualquer material passou a ser veículo para as produções de arte, por que a instituição escolar não se atualizou no que se refere aos usos e aos tipos de materiais para o trabalho pedagógico em Arte?

Tal pergunta originou a pesquisa Conversações: Crianças, Materiais e Arte Contemporânea (20I I-20I5), desenvolvida em duas escolas públicas e um atelier infantil privado. Nosso objetivo foi desenvolver as possibilidades de investigação-criação-expressão de crianças pequenas (4-5 anos) tendo os materiais como propulsores dos processos infantis. Pretendíamos saber como as crianças 
elaboravam suas linguagens plásticas, lidavam com materiais tradicionais e materiais que estão pouco habituadas a explorarem, manipularem, investigarem e criarem. Como referência para pensarmos e desenvolvermos a pesquisa, utilizamos a Arte Contemporânea, seus materiais e alguns artistas que utilizavam materiais incomuns.

Antes da pesquisa, havíamos notado que os materiais-veículo tradicionais ainda eram pouco explorados e materiais comuns do cotidiano sequer são entendidos como material para as proposições de Arte, sendo que, muitas vezes, são vistos pelas professoras por seus aspectos funcionais e não como possibilidade inventiva. Assim, o grampeador é para o adulto grampear folhas e não é entendido como um instrumento para desenhar; brinquedos danificados são descartados quando poderiam ser transfigurados ou justapostos formando objetos híbridos; sobras rasgadas, amassadas de papéis são desprezadas quando serviriam para imaginar o que aquelas formas sugerem; fitas adesivas são usadas para prender folhas nas paredes ou unir caixas e não são aproveitadas como linhas para estruturar formas em suportes que não sejam papéis, mas a própria mesa, espelhos, parede, piso da sala.

Em duas situações em diferentes contextos educativos, foi pensada uma cena pedagógica, inspirada na concepção de desenho expandido e do trabalho com plotter de Regina Silveira, que desafiasse as crianças a desenharem com um material-veículo que comumente é para unir ou prender papéis, objetos, fios. Em um grupo, oferecemos uma fita preta e levemente flexível que é utilizada para isolar fios elétricos: a fita isolante. No outro grupo, disponibilizamos fitas adesivas coloridas, nas sessões de pesquisa, nos três contextos educativos, criamos um problema para que as crianças resolvessem: não oferecer suportes para colarem as fitas, pois acreditamos que qualquer ação pedagógica em Arte deve ser provocativa. Como as crianças, na maioria das vezes, desenham e pintam sobre suportes, retiramos esse espaço de ações previsíveis para que elas procurassem outras soluções e configurações.

Em ambas as situações, as crianças perguntaram: Onde vamos colar as fitas? Pesquisadoras responderam: Além das folhas de papel, onde poderemos colocar? As crianças ficaram atônitas com a resposta e em como resolveriam a falta do suporte-papel, pois comumente usavam fitas para colar papeis nas paredes e, na maioria das vezes, usavam suporte para qualquer proposição em arte. Também ficaram curiosas com os materiais, em especial, com a fita isolante que desconheciam. Com o desafio lançado, as crianças ficaram empolgadas em procurar outros suportes nos espaços escolares.

A seguir, alguns desenhos infantis com as fitas: 
Figura 2: Desenho de crianças com fita isolante sobre paredes e portais
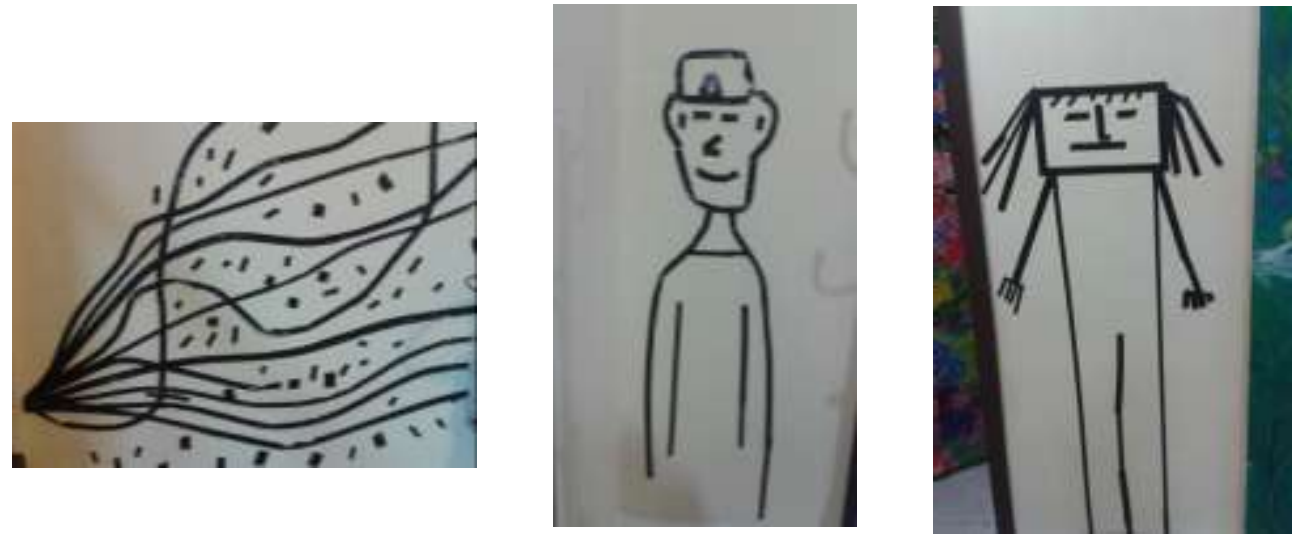

Fonte: Espaço de Arte Azul Anil, arquivo da autora, 2015.

Observo que, ao utilizarem materiais novos sobre suportes, que até então não tinham sido pensados como "materiais de Arte", as ações das crianças foram de investigar e procurar entender como as fitas comportavam-se sobre espelhos, paredes e mesas, onde era possível colar, descolar, se poderiam fazer ângulos, curvas, qual o tamanho de fitas ficava mais fácil/difícil para manipular, entre outras investigações nos fazeres com os novos materiais e suportes. As relações de conhecimento que as crianças estabelecem com os materiais são explicados por Gandini:

Investigar e descobrir como um determinado material se apresenta e é transformado, ajudando a criança a adquirir conhecimento sobre o material em si - sobre a textura, forma, configuração, cor e aparência externa e interna. A criança aprende gradualmente que o material pode ser usado de muitas maneiras diferentes (GANDINI, 2012, p. 29).

Em relação às formas criadas, observamos que surgiram formas de grandes formatos, autorais, angulares, onduladas, representativas, assim como não representativas com a fita isolante nas paredes e formas geometrizadas com fitas adesivas coloridas nas mesas e espelho. Atribuímos essas diferenças porque a maleabilidade, textura e aderência das fitas eram diferentes, assim, os resultados dos percursos de criação foram diferentes.

Outro aspecto que as crianças resolveram foi a ocupação/distribuição das fitas nos suportes, tendo em vista que, apesar das paredes, mesas e espelhos terem grandes formatos, havia delimitações e, para desenhar com fitas em um espaço bem mais amplo que as folhas A4, elas precisavam utilizar o corpo inteiro. Assim, elas precisavam, inicialmente, projetar o que fariam e como organizar a colagem das fitas. No decorrer das ações das crianças, aquilo que haviam projetado alterava-se, porque, muitas vezes, as fitas e o suporte escolhido não "obedeciam" a vontade das crianças. Em anotações do diário de campo: Com o passar dos encontros, percebemos que cada vez mais as crianças vêm se permitido experienciar os materiais oferecidos, os materiais têm deixado de serem apenas novas informações, notamos 
que nossos encontros estão se tornando significativos, pois vemos que as crianças buscam realizar trabalhos que ultrapassem as reproduções encontradas no ambiente escolar. (Arquivos da autora, 20/3).

Consideramos que ao se depararem com materiais que as crianças desconheciam, elas empenharam-se, criaram hipóteses e investigaram as possibilidades de como usá-los para resolver as questões impostas por eles, percebemos que aconteceram aprendizagens diante das imposições dos materiais. De acordo com Cunha (2017, p. 18): "Tais descobertas e constatações, realizadas pelas crianças atravessadas pela ludicidade, poderão auxiliar as professoras a também conhecerem os materiais e assim formularem propostas pedagógicas a partir dessas descobertas".

Muitas vezes, as professoras partem do pressuposto que ofertar inúmeros materiais tradicionais poderá despertar o interesse e a vontade das crianças em descobrir as possibilidades inventivas deles, porém, ao reduzirmos os materiais, no caso, as fitas, vimos que as crianças mobilizaram-se em descobrir e criar outros usos para um material-veículo que elas não estavam familiarizadas. Assim como o artista Cildo Meireles explorou capas de revista e elas transformaram-se em oceano na obra Marulho, as crianças também adulteraram as funções de uso das fitas, transformando-as em linhas que configuraram formas. Muitas vezes, reduzir os materiais significa ampliar a exploração e a imaginação das crianças.

É urgente compreendermos o que é o desenho hoje, pensá-lo numa perspectiva expandida e que não deve estar restrito aos riscantes sobre papel branco, retangular, formato $A 4$, sulfite de gramatura 75g. Essa ideia sobre o desenho deve ser modificada e ampliada nos contextos escolares. Desenho é um bordado, desenho é a marca da unha na pele, desenho é os fios do cabelo em um penteado, desenho é modelar um arame, desenho é o corpo em movimento, desenho é pedacinhos de folhas que o vento forma.

Atualmente, nas redes sociais, grupos de professoras de crianças compartilham atividades de "como deve ser o desenho na Escola" como desenhos prontos, moldes de formas para as crianças colorirem, indicações de desenhos temáticos e de datas comemorativas que não emergem das demandas das crianças, entre tantas outras atividades, ultrapassadas e enfadonhas para as crianças. As sugestões são pautadas em uma ideia da educação tecnicista, antiga, que pretende adestrar mãos e olhos das crianças. Tais atividades não contemplam a exploração de materiais e sequer tangenciam os processos de criação. Diante de atividades tão dissonantes do campo de discussões atuais da Arte, Infância, Pedagogia e dos documentos da legislação brasileira é forçosa uma mudança nas ações pedagógicas ema Arte. 


\section{Transformações da pintura}

Assim como foram ampliadas as possibilidades dos usos de materiais do cotidiano, os materiais tradicionais, como os riscantes: lápis de cor, grafite, giz de cera, pastel seco e oleoso, carvão e os pictóricos como as tintas, também foram inovados na Arte Contemporânea. Podemos pensar como diferentes artistas utilizaram o mesmo material-veículo: tinta sobre tecido, canvas, de modos diferentes em suas pinturas. Entre inúmeros artistas que utilizam a pintura, menciono Nadin Ospina, Nuno Ramos, Gisela Waetge, Gottfried Helnwein, David Hockney, Maria Tomaselli Cirne Lima, Siron Franco, Adriana Varejão, Basquiat, que utilizam os mesmos materiais, contudo, explorados de formas distintas.

A pintura foi uma das linguagens mais utilizadas na Arte Ocidental, assim nos mostra a História da Arte que é quase a "história da pintura". Com o rompimento dos Impressionistas, na metade do século XIX, com a forma realista de pintar, bem como os modos de marcar as superfícies em formas singulares e onde a pincelada de cada artista tornar-se uma espécie de impressão digital, podemos afirmar que a pintura iniciou um processo de transformação incessante e contínuo. Evidentemente, uma pintura que se constituía de borrões, manchas, formas sem contornos definidos não foi aceita na época por destoar de toda a tradição secular. Além de ser uma pintura diferente dos padrões vigentes, as temáticas chocavam o público por não se focarem em paisagens, personagens e cenas idealizadas, mas mostravam pessoas comuns e acontecimentos rotineiros. Contudo, apesar de rechaçado, o legado Impressionista abriu as possibilidades para olhar, representar e pintar/manchar o mundo de outras maneiras.

Apesar das mudanças no campo da pintura, a tinta, material-veículo dessa linguagem, com toda sua potência em cobrir superfícies e criar cores, muitas vezes é pouco explorada nos contextos escolares. Notamos que, nas situações de pintura, por exemplo, a consistência das tintas industrializadas, em geral, o guache, é aquela que sai do pote, assim como a textura é sempre a mesma, uma vez que não são feitos acréscimos no pote. Abre-se o pote e nada é feito para incrementá-lo em relação à consistência, qualidade e textura.

Muitas vezes, as experiências e os processos de descobertas das cores também são negligenciados. Nas escolas, vemos folhas A4 para serem preenchidas pelas crianças "aprenderem" a misturar as cores, com duas formas geométricas, cada uma com uma cor primária, intercaladas pelo sinal + , finalizada com sinal $=$ e uma outra forma para ser pintada da cor resultante das outras duas cores.

Porém, as ações pedagógicas em Arte não devem estar centradas nesses exercícios inadequados em pintar pequenas formas geométricas ou desenhos prontos para serem pintados. No que se refere à pintura, a forma é consequência do gesto e nunca deve estar aprisionada em uma linha do desenho. Sobre o ato de pintar das crianças, Richter $(2014$, p. 88) afirma que: "Pintar é 
essencialmente misturar, temperar as cores, relacionando-as no espaço do suporte. Nada mais mágico para a criança do que fabricar, ser um fazedor de cor, para descobrir por meio da exploração ou perseguir determinado matiz, experimentando ludicamente a matéria colorida até alcançar a cor desejada".

Outro trabalho recorrente com pintura nas escolas é a utilização das mãos das crianças como carimbos, porém são as professoras que colocam as mãos das crianças na tinta e escolhem como e onde carimbar sobre o papel, depois complementam as formas com elementos de alguns animais como bicos, patas, focinhos. Ou seja, as crianças só tiveram a oportunidade de ter contato com a tinta pelas ações dirigidas pela professora e não de usufruir as possiblidades do ato de pintar e da tinta, sua textura, cor, cheiro, consistência e formas de marcar o suporte. É inconcebível que perdurem nas escolas esses tipos de atividade em que as crianças são usadas como instrumento pelo adulto e impossibilitadas de experienciar os materiais e os movimentos corporais.

Figura 3. Pintura dirigida pela professora

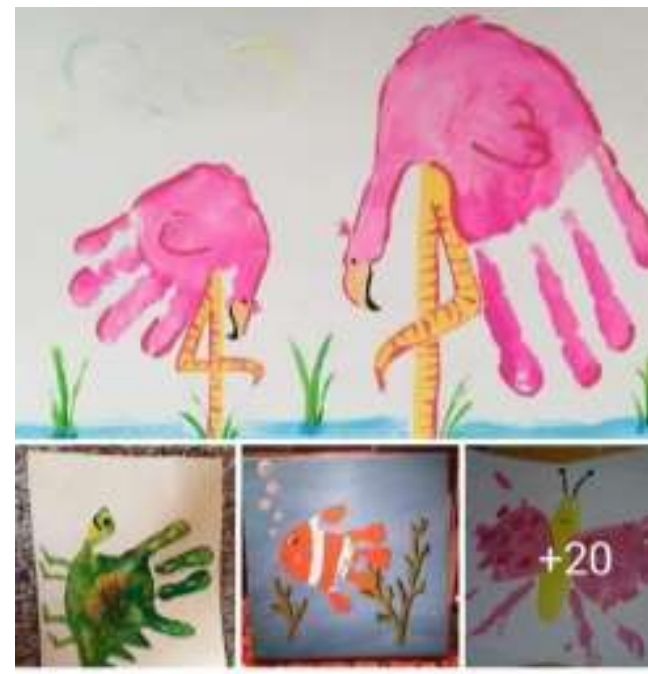

Fonte: Grupo de professoras em redes sociais, 2019.

Sublinho que o trabalho em Arte com crianças também é uma experiência do corpo com os materiais. E perguntamos: Que aprendizagens são estas no campo da pintura que não passam pelos corpos das crianças, pela autoria, pela pesquisa, pela criação? 
Figura 4: Crianças pintam com o corpo

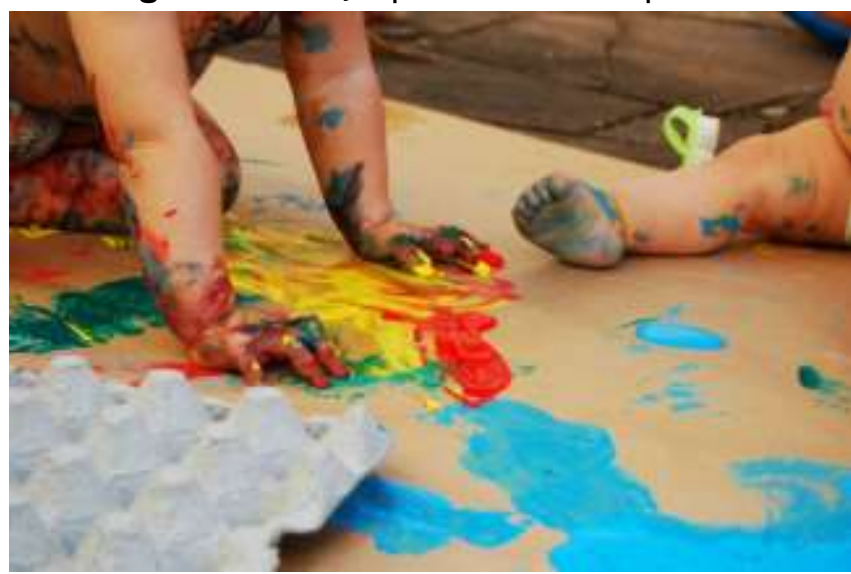

Fonte: Atelier Azul Anil, arquivo da autora, 2004.

Em oposição aos trabalhos de pintura, baseados em concepções ultrapassadas de ensino de arte nas quais desconsideram a autoria, a pesquisa de materiais e os processos de criação das crianças, apresento o trabalho desenvolvido no Estágio Curricular do Curso de Pedagogia, relatado no TCC, no qual Moreira inspira-se em artistas e obras contemporâneas para desenvolver as suas propostas. Segundo a autora:

O ateliê foi o lugar (ou os lugares) no qual as crianças experimentaram, exploraram, se expressaram, comunicaram suas ideias e possibilidades a partir do uso e contato com diferentes materiais, que aqui são considerados também uma linguagem. Cada proposta era composta por materiais plásticos (tintas, pigmentos...) e materialidades (tecidos, linhas, rolhas, bolas...) espaços (sala, pátio), ambientação (luzes, músicas), sentimentos/ ritualísticas (mandalas...)

(...) Não há uma lista de materiais específicos, didáticos ou modelos de trabalho que envolvem arte com crianças obrigatórios, a serem seguidos. Contrário a isso, o trabalho com arte contemporânea na educação infantil pode perpassar pelos mais diversos materiais - inclusive materiais do cotidiano, que não precisam ser comprados - e inspirações (MOREIRA, 2018, p. 16).

Em relação aos marcadores de superfície, os pincéis são os principais instrumentos que encontramos nas escolas, no entanto poderiam ser ampliados começando pela exploração do principal instrumento, assim como o suporte: o corpo, não só as mãos, porque os processos de criação/expressão das crianças fazem-se com braços, barriga, pernas, cabelos, pescoço, pés, cotovelos.

Assim como a Arte de hoje busca outros instrumentos, a Escola também necessita atualizarse e buscar experimentar objetos que servem para limpar copos, garrafas, mamadeiras, superfícies, vasos sanitários, carros, louças, assoalho, instrumentos para reparos e pinturas residenciais como espátulas de silicone, trinchas, broxas, pincéis largos, artefatos de cozinha como garfos, colheres, borrifadores, brinquedos entre tantos outros objetos de "longo alcance", "provadores", "desacomodares" de uso cotidiano que podem vir a transformar-se em instrumentos com grandes possibilidades para marcar as superfícies com tintas. 
Figura 5: Marcadores para pintar e criança utilizando limpadores de mamadeiras
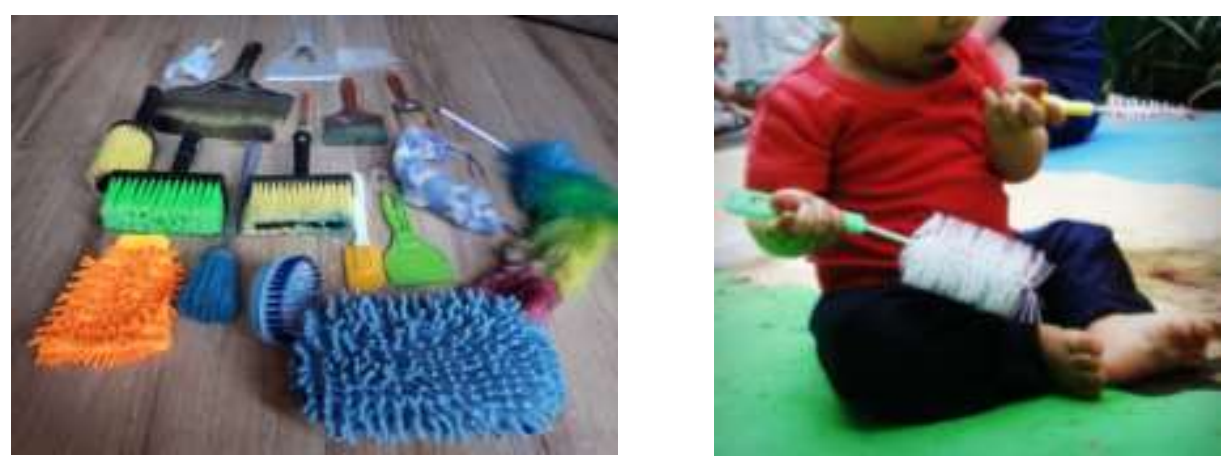

Fonte: arquivos da autora, 2014.

Além da utilização de outros instrumentos, marcadores, para desenvolver propostas com a pintura, recordo que a ação de pintar também pode ser realizada SEM instrumentos, como por contato, borrifação e respingos e movimentos do suporte.

Figura 6: Pintura de contato
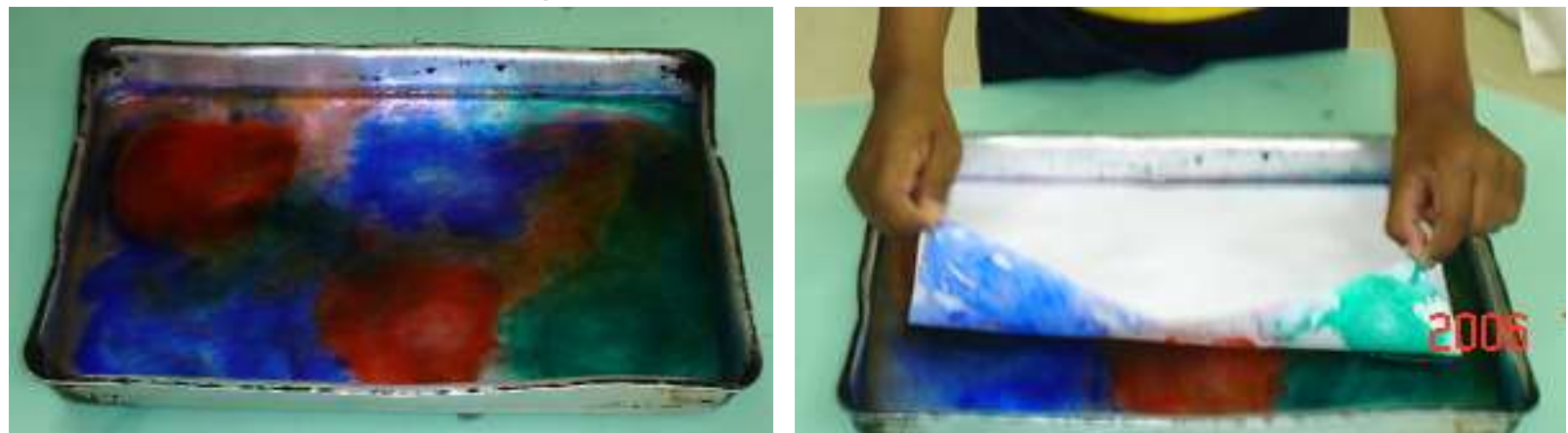

Fonte: Arquivos da autora, 2006.

Em relação aos suportes, os materiais não deveriam estar restritos aos papéis brancos, sem textura e retangulares, uma ideia de suporte que foi hegemônica na Arte até o século XIX, mas estamos no século $X X I$ e os suportes passaram a ser qualquer material. Caixas, tubos, garrafas, pedaços de madeira, paredes, calcadas, muros, tecidos, guarda-chuvas, livros, propagandas, sacolas, pedras, folhas e troncos de árvores, objetos de qualquer natureza devem ser experimentados e transformados pelas crianças.

\section{Pintura é só com tintas e pincéis?}

Nem sempre a pintura necessita de tintas e marcadores. Um dos artistas mais influentes da Arte Ocidental, Henry Matisse, em 194I, por problemas de saúde precisou parar de pintar com tintas, entretanto, ele inventou uma nova vertente da pintura: pintar com a tesoura. A pintura com tesoura 
consistia em recortar papeis coloridos pintados com guache, por sua assistente, e depois colá-las sobre uma superfície, seriam colagens, porém com a linguagem da pintura. Para a Pugliese (2013, p. 3920):

Matisse inicia o que se propõe reconhecer como a quarta virada em sua poética, ao desenvolver a técnica do collage a partir de um processo em que cobria de guache folhas de papel cartão que, uma vez recortados poderiam ser colados sobre suportes de grandes dimensões. (...) ele criava o próprio campo-de-cor, livre de qualquer limite. Com a tesoura, desenhava a própria cor, moldando-a como uma peça de vitral e, finalmente, compunha diretamente o espaço pictórico com ela.

As pinturas com tesoura rompem a ideia da pintura tendo a tinta e pincéis como únicos materiais e suporte, bem como dá visibilidade ao hibridismo das linguagens da Arte.

No início do século XXI, em 2003, em Porto Alegre, Lia Menna Barreto criou a série Pinturas de Taiwan com objetos diversos como flores, animais, bonecas de plásticos e bichinhos de pelúcia, para unir os objetos, ela utiliza o ferro elétrico quente, assim o tridimensional dos objetos passa para $\circ$ plano bidimensional. Segundo a artista: "Quando arrasto um objeto de plástico com o ferro, é como imprimir uma pincelada sobre o tecido". Sobre suas escolhas de objetos infantis e como ela os vê, ela afirma: “(...) eu não estou interessada na complexidade da infância, o que me interessa mesmo são as cores e as formas dos objetos infantis... Quando eu entro numa loja de criança e vejo aquele mundo... é como se fosse uma paleta de pintura pra mim. Me perguntam seguidamente se eu trabalho com a infância, mas eu trabalho com os objetos da infância" (MENNA BARRETO, 20I4, p. I3).

Joana Vasconcelos, artista portuguesa, desenvolveu a série Pinturas de Crochê² (2009-2019) composta por pequenas peças tridimensionais de crochê de lã feitos à mão e outros materiais sobre molduras. São pinturas feitas sem tintas e com materiais que não são considerados do campo da pintura. Ao trazer peças inspiradas em artesanias domésticas ao universo da pintura, uma das principais linguagens da História da Arte, a artista rompe com a distinção entre as obras de arte e artesanato e mostra que não há determinados materiais para constituir as linguagens da Arte e que, por mais simples que sejam os materiais, eles podem adquirir outros usos.

Matisse, Lia Menna Barreto, Joana Vasconcelos, entre tantos outros artistas, têm experimentado outros materiais, alheios ao universo da pintura, para PINTAR. Que outros materiais poderiam ser aproveitados na escola para produzir pinturas?

\section{Meninos/Meninas e os materiais}

Em geral, pensamos que as crianças, meninos e meninas, escolhem e utilizam os materiais da mesma maneira, como se eles fossem "neutros", porém, as escolhas sobre um objeto, uma cor e como

\footnotetext{
${ }^{2}$ Ver http://joanavasconcelos.com/obras_en.aspx?s=CROCHET\%20PAINTINGS

Olhar de professor, Ponta Grossa, v. 24, p. I-25, e-17695.037, 2021.

Disponível em <https://revistas2.uepg.br/index.php/olhardeprofessor>
} 
usá-los, muitas vezes, estão relacionadas com as aprendizagens efetuadas pelas pedagogias culturais generificadas endereçadas à infância. Notei junto com as estagiárias do curso de Pedagogia que os desenhos produzidos pelas crianças no período representativo, em situações espontâneas ou orientadas no cotidiano escolar, apresentavam repertórios gráficos que identificávamos como "femininas e masculinas".

Observamos que a organização espacial e composição, construção das formas, utilização de cores e símbolos, entre outras características, assim como os modos de utilizar os materiais, eram recorrentes e diferentes nos grupos das meninas e dos meninos. Percebemos que havia uma estética infantil generificada, produzida pelos diferentes artefatos culturais que, de muitas formas, reverberavam nas formas de representações das crianças.

Constatamos que os marcadores de gênero, presentes nos diferentes artefatos culturais, estendem-se em suas produções gráfico-plásticas, como o uso de cores suaves como rosa e lilás nos desenhos de meninas, bem como formas padronizadas de corações, flores, borboletas, arabescos. Nas produções dos meninos, notamos a utilização de cores fortes como vermelho, amarelo e preto, figuras humanas em movimento e carros, entre outras configurações visuais.

A partir dessas evidências, foi desenvolvida entre 2006-2010 a pesquisa "Desenhos de meninos e meninas: relações entre imaginário e gênero", realizada com crianças de quatro a seis anos em quatro escolas públicas infantis onde aconteciam os Estágios Curriculares do curso de Pedagogia e pesquisas de TCC do curso de Graduação e Especialização em Educação Infantil. Na pesquisa, buscamos entender como as pedagogias visuais endereçadas à infância influenciavam suas representações visuais. Rech, uma das pesquisadoras, aponta o quanto é visível, nas produções gráfico-plásticas infantis, a diferenciação das cores e símbolos utilizados por meninos e meninas. Segundo ela,

Os desenhos apresentam repertórios estéticos com atributos de representação definidos para o gênero feminino e masculino. Nestes desenhos, e em outros tantos realizados pelas crianças do meu grupo, surgem, repetidamente, marcadores de gênero, que por sua vez aparecem também em roupas, mochilas, calçados, acessórios. Estes marcadores, em geral, apresentam, e representam, o gênero em posição binária, apresentando o masculino movimento, agitação, formas, vários pontos de vista, cores fortes e escuras, temáticas de lutas, etc; e o feminino imobilidade, formas estáticas e frontais, cores suaves, temáticas de flores, corações, etc. (RECH, 2008, p. 26).

Em relação aos materiais, os meninos evidenciavam mais interesse exploratório, quando usavam riscantes, como lápis de cor, giz pastel seco ou carvão, ao desenhar deixavam marcas fortes nos suportes e não se preocupavam com vestígios desses materiais que ficavam em suas mãos, rostos, corpos e roupas. Quando isso ocorria, aproveitavam as marcas e borrões na pele ou nos suportes e inventavam situações ou personagens com os vestígios. Por sua vez, as meninas eram cuidadosas e 
temerosas ao utilizar os materiais riscantes: a ponta precisava estar afinada, os traçados eram suaves e não gostavam que os vestígios impregnassem suas roupas e pele.

Em outra situação de pesquisa de TCC de conclusão do curso de Licenciatura em Artes Visuais, em um atelier privado, foram elaboradas cenas pedagógicas com o intuito de problematizar as relações de gênero com os materiais baton e carrinhos de brinquedo. Duas características da Arte Contemporânea serviram para elaborar essa proposição feita para as crianças: modificar o uso dos materiais cotidianos com $\circ$ intuito de problematizar e levantar questões acerca de temáticas observadas, relações de gênero, e o hibridismo das linguagens artísticas: pintura + desenho. Segundo o relato da pesquisadora: "Busquei realizar atividades práticas com os alunos envolvendo as discussões de gênero e escolhi dois materiais inusitados para realizá-la. Distribui, num primeiro momento, diversos batons às crianças, com tonalidades terrosas. A proposta consistia na elaboração de um “desenho-pintura" utilizando esse material" (CUNHA, 2014, p.74).

O desafio, além de ser um material que elas nunca haviam utilizado como marcador, também foi como elas marcariam os suportes: os batons não deveriam tocar os papéis, mas partes do corpo das crianças, assim foi proposto que explorassem as possibilidades que os seus corpos ofereciam, que usassem nariz, orelha, pé: "Dessa maneira, pretendi desmistificar a proibição do uso dos batons pelos meninos, que tem, naturalmente, assim como as meninas, a vontade e a curiosidade de marcar o corpo, mas que são podados pelos professores ao demonstrar interesse pela maquiagem" (CUNHA, op. cit., p. 75).

No decorrer da proposição, foram observados diferentes modos das crianças utilizarem o baton no corpo. As meninas de oito a dez anos não modificaram o uso comum do baton em pintar lábios e os trabalhos foram extremamente semelhantes, cheios de beijos carimbados nas folhas. Já as meninas de cinco a sete anos começaram a borrar propositalmente ao redor da boca, criando novos formatos para ela. Em seguida, partiram para o resto do corpo e divertiram-se descobrindo as marcas que podiam fazer. Os meninos de oito a 10 anos pintaram apenas os seus dedos, com muito cuidado para que não houvesse manchas em quaisquer outras partes do corpo, e até da mão. Os meninos de cinco a sete anos também começaram apenas com as pontas dos dedos, mas logo borraram toda a mão e subiram para os braços (CUNHA, idem).

Após a experiência com os batons, foram distribuídos carrinhos de brinquedo 3 às crianças para serem explorados e utilizados como marcadores em uma pintura coletiva em papel pardo de grandes dimensões. Pintadas com tinta guache, as rodas dos carrinhos deixavam as suas marcas por onde passavam. Em todos os grupos, tanto meninos quanto meninas exploraram os carrinhos e os rastros

\footnotetext{
${ }^{3}$ A ideia de utilizar carrinhos de brinquedo como marcadores foi inspirada na exposição DERRAPAGEM (20042005) de Regina Silveira.
}

Olhar de professor, Ponta Grossa, v. 24, p. I-25, e-17695.037, 2021.

Disponível em <https://revistas2.uepg.br/index.php/olhardeprofessor> 
de tinta, compondo o papel com diversos outros elementos que se relacionavam uns com os outros (CUNHA, ibidem).

Figura 7: Pintura/desenhos com batons e carrinhos
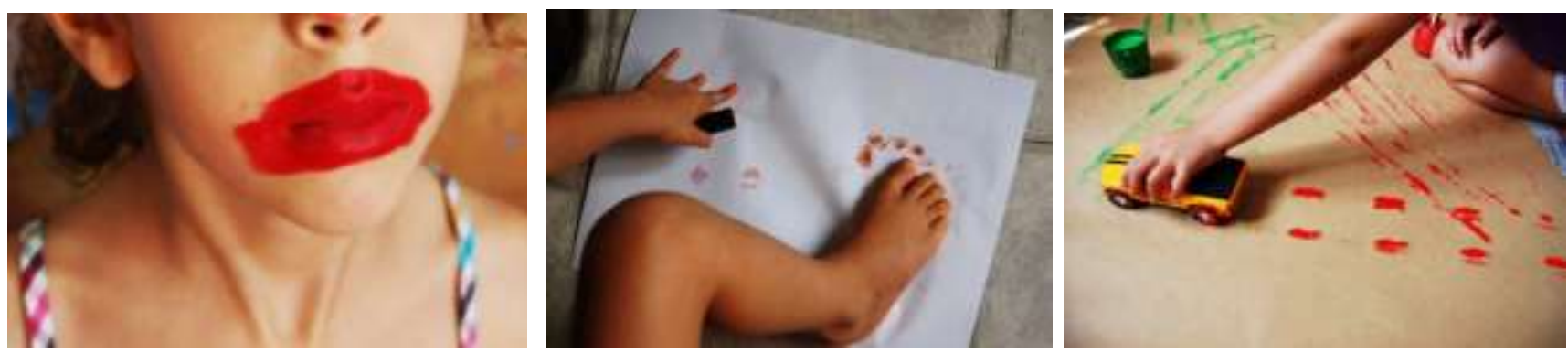

Fonte: Espaço de Arte Azul Anil, arquivo da autora, 2015.

Desse modo, é fundamental prestarmos atenção o quanto meninos e meninas, influenciados pelas pedagogias culturais/visuais, deixam de experimentar materiais e cores, variar formas e os modos de organização espacial em suas produções. Um dos caminhos possíveis é ampliar repertórios, colocando as crianças em contato com produções de Arte que não apresentam marcadores de gênero como aqueles dos artefatos direcionados a elas. Artistas Modernistas que exploraram a cor e composições, como Vicent Van Gogh, Wassily Kandinsky, Paul Klee, René Magritte, Marc Chagall, Joan Miró, Henry Matisse, Frida Kahlo, Tarsila do Amaral, Djanira, entre tantos outros/as, seriam disparadores para que as crianças ampliem e usufruam a ampla possibilidade da paleta de cores e possam abandonar os ditames da cultura para infância.

Além da ampliação de repertórios, desafiá-los a elaborarem suas produções com materiais que, muitas vezes, nossa cultura classifica como sendo para mulheres/meninas ou para homens/meninos. Élida Tessler, Cildo Meireles, Nuno Ramos, Chiaru Shiota, Ana Mendieta, Leon Ferrari, Marta Minujín, Jac Leirner, Nikki de Saint Phalle, entre outros/as, são artistas que utilizam os mais variados materiais para produzirem seus trabalhos, sendo que algumas vezes os trabalhos objetivam desencadear discussões sobre as relações de gênero.

Ademais, seria produtivo propor trocas entre meninos e meninas em relação aos usos dos materiais e, assim, as descobertas de cada um seriam compartilhadas e ampliadas, desterritorializando as fronteiras de gênero que confinam meninos/as às estereotipias de gênero.

\section{Quais teus materiais e como eles poderão ser desafiadores?}

As concepções da Arte mudaram e os materiais passaram a ter uma amplitude nunca imaginada a partir do início do século $\mathrm{XX}$, contudo, essa transformação radical foi pouco absorvida pela Escola e vemos as poucas mudanças consolidadas nas listas de materiais escolares de Arte e a ausência dos 
materiais da Arte. É urgente alinhar as listas e usos dos materiais com as concepções de Arte da contemporaneidade, tendo em vista que nossas crianças vivem e interagem com a cultura do século XXI.

Para que o trabalho pedagógico em Arte com as crianças tenha uma consistência sólida e não seja apenas um modismo é necessário que as professoras aproximem-se da Arte de hoje, pois realizando esse avizinhamento mudarão suas concepções de arte e, consequentemente, seus modos de pensar e organizar seus trabalhos pedagógicos. $O$ trabalho pedagógico em Arte deveria estar sustentado na Arte.

Oferecer e criar proposições com materiais tradicionais e/ou comuns do cotidiano requer pesquisa, conhecimento, seleção de materiais, exploração, adequação, criação de situações desafiadoras para que cada criança imprima suas marcas pessoais. Ter materiais, equipamentos e espaços favoráveis para desenvolver cenas pedagógicas é importante e facilita a ação das professoras, contudo não é suficiente para as crianças configurarem suas singularidades poéticas. É necessária à escuta sensível e atenta em relação às demandas das crianças, leitura das suas produções gráficoplásticas para poder ampliar aquilo que elas já fazem e sabem, diálogos com o pensamento e obras dos artistas, mediações provocativas que desconstruam estereotipias herdadas dos repertórios da cultura para a infância e escolar.

Pesquisa e conhecimento de materiais demandam tempo, mas esse tempo pode ser o próprio tempo com as crianças ao ar livre, na sala referência, nos corredores, nas janelas. Um tempo de descobertas compartilhadas, de surpresas mútuas, de autorias individuais e coletivas onde não se demarca a influência do adulto ou da criança nas produções efêmeras, perenes, concretas, gasosas, molhadas, secas, duras, moles, grandes, pequenas, minúsculas, iluminadas, escuras, claras, coloridas, monocromáticas.

E, para finalizar nosso diálogo sobre Arte, artistas, materiais, cenas pedagógicas, faço a pergunta: Quais teus materiais e como eles poderão ser desafiadores?

\section{Referências:}

ÁlVAREZ, Irene F. Curso Introducción Bases Creactectura. Plataforma: https://formacion.createctura.es/ Outubro 2020

BARRETO, L. M. A Palavra está com elas: diálogos sobre a inserção da mulher nas artes visuais. Porto Alegre: Panorama Crítico, 2014.

BORGES, Camila Bettin. Respingos, colagens, vozes, sensações. CUNHA, S. R. V.; CARVALHO, R. S. de (Org.) Arte contemporânea e educação infantil: crianças observando, descobrindo e criando. Porto Alegre: Editora Mediação, 2017. 
BOHNS, N. Dos objetos nascem objetos. Blogspot Lia Menna Barreto. 2003. Disponível em https://lia-mennabarreto.blogspot.com/2008/02/neiva-bohns.html Acesso: I de marco 202 I

CANTON, K. Temas da arte contemporânea e mundo de artista: a narrativa como método para o ensino da arte. Espaços da mediação a arte e seus públicos. 2013. Disponível em: https://repositorio.usp.br/item/002647457 Acesso: 5 de março de 202 I

CHARELLI, T. Apropriação/Coleção/ Justaposição. Catálogo da Exposição Apropriações/Coleções. Porto Alegre: Santander Cultural, 2002.

CUNHA, M. E. R. V. Esconde/mostra: a diferença no ensino de Artes. Porto Alegre: Trabalho de Conclusão de Curso Licenciatura em Artes Visuais, Instituto de Artes, Universidade Federal do Rio Grande do Sul, 2014.

CUNHA, S. R. V. Como vai a arte na Educação Infantil? Arte e Educação Infantil. Revista Apotheke e-periódico. Universidade do Estado de Santa Catarina. Centro de Artes. Programa de PósGraduação em Artes Visuais, v. 5 n. 3, 2019

CUNHA, S. R. V. Uma arte do nosso tempo das as crianças de hoje. CUNHA, S. R. V.; CARVALHO, R. S. de (Org.) Arte contemporânea e educação infantil: crianças observando, descobrindo e criando. Porto Alegre: Editora Mediação, 2017.

DIEFENTHÄLER, Daniela da Rosa Linck. A gente pode fazer casa do jeito que a gente quiser'? : ações propositoras e materiais provocadores ampliando o imaginário infantil. Porto Alegre: Dissertação de Mestrado, Faculdade de Educação, Universidade Federal do Rio Grande do Sul, 2009. Disponível em: http://hdl.handle.net/10183/200727 Acesso: I5 de fevereiro 2021

FERREIRA, G. COTRIN, C. Escritos de artistas: anos 60/70. Rio de Janeiro: Jorge Zahar, 2006.

GANDINI, L. [et al.], O papel do ateliê na Educação Infantil: a inspiração de Reggio Emilia. Trad. Ronalldo Cataldo Costa.Porto Alegre: Penso, 2012.

HERKENHOFF, P. Quase brinquedos de Lia Menna Barreto. In: BARRETO, L. M. Lia Menna Barreto: ordem noturna. Rio de Janeiro: Thomas Cohn Arte Contemporânea, 1995. Disponível em: https://www.escritoriodearte.com/artista/lia-menna-barreto._Acesso: I de marco 2012.

HOLM, A. M. Baby-Art: Os primeiros passos com a arte. São Paulo: Museu de Arte Moderna de São Paulo, 2007.

LEONTIEV, A. N. Os Princípios Psicológicos da Brincadeira Pré-escolar. In: VIGOTSKI, L. S; LURIA, A. R; LEONTIEV, A. N. (Org.). Linguagem, Desenvolvimento e Aprendizagem. São Paulo: Ícone, 1994.

MARCOLINO, A. C.; SILVA, J. M. R. William Kentridge e a materialização do tempo no espaço. Revista Educação Gráfica, v. 20, n. 03, 2006. Disponível em: http://www.educacaografica.inf.br/artigos/william-kentridge-e-a-materializacao-do-tempo-no-espacowilliam-kentridge-and-time-materialization-in-the-space Acesso: 02 de março de 202I.

MENNA BARRETO, L. Lia Menna Barreto faz sinergia de arte e vida. Entrevista a Juliana Monachesi. Folha de São Paulo. São Paulo: llustrada, 2000. Disponível em https://wwwl.folha.uol.com.br/fsp/ilustrad/fq I003200032.htm_Acesso: 2 de marco 202I. 
MOREIRA, A. Arte contemporânea e registros de crianças: autacom_petit, um ateliê suprasensorial. Trabalho de Conclusão de Curso Licenciatura em Pedagogia, Faculdade de Educação, Universidade Federal do Rio Grande do Sul, Porto Alegre, 2018.

OSTETTO, L. E. Educação infantil e arte: sentidos e práticas possíveis. Caderno de formação de Professores de Educação Infantil: Princípios e Fundamentos. Acervo digital Unesp. São Paulo: Cultura Acadêmica, v. 3, 2010.

PUGLIESE, V. Notas sobre a poética de Henri Matisse e sua relação com matrizes orientais. In: $\mathbf{2 2}^{\circ}$ Encontro Nacional de Pesquisadores em Artes Plásticas. Anais. Belém do Pará: Ed. Belém: ANPAP/PPGARTES/ICA/UFPA, 2013. Disponível em: http://www.anpap.org.br/anais/20I3/ANAIS/simposios/I0/Vera\%20Pugliese.pdf Acesso: 3 março 202I.

RECH, B. B. Imaginário infantil: desenhos de meninos e meninas. Porto Alegre: Trabalho de Conclusão de Curso Especialização em Educação Infantil, Faculdade de Educação, Universidade Federal do Rio Grande do Sul. 2008.

RICHTER, S. R. S. Crianças pintando: Experiências Lúdica com as cores. CUNHA, S. R. V. (Org.). As artes no universo infantil. Porto Alegre: Editora Mediação, $3^{\mathrm{a}}$ Edição, 2014.

TIBURI. M. Arte Contemporânea: sobre nossa dificuldade de pensar e fazer. Revista As Partes (on line). Porto Alegre: Atelier Livre da Prefeitura Municipal de Porto Alegre, número 7, Dez/20I2. Disponível em: http://lproweb.procempa.com.br/pmpa/prefpoa/smc/usu_doc/as_partes_7_dez_20I2.pdf Acesso: 5 de marco de 2021 .

VERAS, E. Percurso da Artista Teresa Poester. Canal Contemporâneo. Porto Alegre: Setembro 2019. Disponível em: http://www.canalcontemporaneo.art.br/arteemcirculacao/archives/00945 I.html Acesso: 2 de março de 202I.

Recebido em: 26 de março de 202I.

Versão corrigida recebida em: 28 de março de 2021.

Aceito em: 28 de março de 2021 .

Publicado online em: 23 de abril de 2021

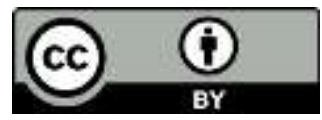

Olhar de professor, Ponta Grossa, v. 24, p. I-25, e-17695.037, 2021.

Disponível em <https://revistas2.uepg.br/index.php/olhardeprofessor> 